\title{
Lymphedema in three previously Wuchereria bancrofti-endemic health districts in Mali after cessation of mass drug administration
}

Housseini Dolo ${ }^{1,2^{*}}$ (D, Yaya Ibrahim Coulibaly ${ }^{1,4}$, Fatoumata Nene Konipo ${ }^{1}$, Siaka Yamoussa Coulibaly ${ }^{1}$, Salif Seriba Doumbia', Moussa Brema Sangare ${ }^{1}$, Lamine Soumaoro', Michel Emmanuel Coulibaly', Abdallah Amadou Diallo', Yaye Diarra', Modibo Sangare', Seydou Doumbia', Robert Colebunders² and Thomas B. Nutman ${ }^{3}$

\begin{abstract}
Background: Lymphedema is a public health problem in countries with lymphatic filariasis (LF) including Mali. We studied the epidemiology and clinical presentation of lymphedema in three previously LF-endemic health districts of Mali after at least five consecutive rounds of mass drug administration (MDA) with albendazole and ivermectin.

Methods: From 2016 to 2018, we used passive and active case finding methods to identify lymphedema cases in three health districts with high pre-MDA LF prevalence: Kolondieba (66\%), Bougouni (44\%) and Kolokani (34\%).

Results: Three hundred and thirty nine cases of lymphedema were identified, 235 (69.32\%) through active case finding. Their median age was 56 years (range 2-90) and 286 (84.36\%) were women. Lymphedema was reported in $226(78.5 \%)$ people aged 41 years and older compared to 73 (21.5\%) people below the age of 41 years $\left(\mathrm{Chi}^{2}=17.28\right.$, $\mathrm{df}=5, p=0.004)$. One hundred and seventy five cases of lymphedema were found in Kolondieba (66 per 100,000 people), 116 in Bougouni (19 per 100,000) and 48 in Kolokani (16 per 100,000). Stage III lymphedema was observed in 131 (38.64\%), stage II in 108 (31.86\%), stage IV in 46 (13.57\%), stage I in $23(6.78 \%)$, stage V in $21(6.19 \%)$ and stage $\mathrm{VI}$ in ten (2.95\%). In the three study districts, lymphedema affected the legs in 281 (82.89\%), the arms in 42 (12.39\%) and both in 16 (4.72\%) (Chi2 = 13.63, $p=0.008)$.

Conclusion: Health districts in Mali with the highest pre-MDA LF prevalences had the highest prevalence of lymphedema. Efforts to actively identify lymphedema cases should be scaled up in previous LF-endemic areas, and should be supplemented by a morbidity management and disability prevention plan at the peripheral health system level.
\end{abstract}

Keywords: Lymphedema, Distribution, Clinical investigation, Mali, Active and passive case detection

\footnotetext{
* Correspondence: hdolo@icermali.org

${ }^{1}$ Filariasis Unit, International Center of Excellence in Research, Faculty of

Medicine and Odontostomatology, BP :1805, Point G, Bamako, Mali

${ }^{2}$ Global Health Institute, Faculty of Medicine \& Health Sciences, University of

Antwerp, Antwerp, Belgium

Full list of author information is available at the end of the article
}

(c) The Author(s). 2020 Open Access This article is distributed under the terms of the Creative Commons Attribution 4.0 International License (http://creativecommons.org/licenses/by/4.0/), which permits unrestricted use, distribution, and reproduction in any medium, provided you give appropriate credit to the original author(s) and the source, provide a link to the Creative Commons license, and indicate if changes were made. The Creative Commons Public Domain Dedication waiver (http://creativecommons.org/publicdomain/zero/1.0/) applies to the data made available in this article, unless otherwise stated. 


\section{Background}

Lymphedema or elephantiasis results from the accumulation of interstitial fluid in the affected anatomic compartment causing localized swelling $[1,2]$. Lymphatic filariasis (LF)-related lymphedema is caused by three filarial species, namely Wuchereria bancrofti, Brugia malayi and Brugia timori [3]. Podoconiosis is another condition in Africa causing lymphedema. However it occurs only in regions with both high altitude and significant rainfall and therefore, is considered not to occur in Mali $[4,5]$.

LF-related lymphedema affects over 15 million people worldwide [3]. In Mali, no lymphedema national surveillance system exists, but LF is considered to be implicated in most lymphedema cases. In Bamako, 0.58\% of outpatients in the dermatology clinic at Gabriel Touré teaching hospital were reported to have lymphedema in 2018 [6]. As part of the country's certification process for the elimination of lymphatic filariasis as Mali's longterm objective, it is important to understand the burden of lymphedema and to manage this concern with the second goal of GPELF (MMDP) [3].

In LF-related lymphedema, the lymphatic system is damaged because the host either fails to modulate the inflammatory response towards either the filarial parasite or its endosymbiont Wolbachia or because secondary infections by bacteria and/or fungi drive the ongoing inflammatory processes [7]. Lymphedema often leads to social stigmatization, mental health problems, loss of income and increased medical expenses for patients and their caregivers [3].

LF prevalence mapping in 2004 showed that all 8 administrative regions of Mali were endemic for W. bancrofti, with an overall nationwide prevalence of $7.07 \%$ (1\% in the north and $18.6 \%$ in the south of Mali) [8]. From 2005 to 2015, MDA with albendazole plus ivermectin decreased the prevalence of $W$. bancrofti infection to zero in Mali in adults tested for microfilaremia (Dembele, 2016 Unpublished). LF transmission assessment surveys (TAS) performed in the 3 health districts between 2010 and 2015 found antigenemia rates $<2 \%$ in $6-7$ year old children suggesting the interruption of LF transmission according to World Health Organization guidelines [9].

The control of LF morbidities, particularly hydrocele and lymphedema, should be an essential component of LF elimination programme. However, in Mali, morbidity management, more particularly that of lymphedema, is not considered as a priority within a national program that focusses on the MDA strategy. Therefore the burden of disease caused by LF morbidities in Mali is unknown. We hypothesised that the highest burden of disease would be present in districts of Mali with previously high LF prevalence.

In preparation of a multi-site clinical trial number NCT02927496 registered by October 7, 2016 to investigate the impact of doxycycline on the regression of early stages of lymphedema, we screened three health districts of Mali (Kolondieba, Bougouni and Kolokani) with previously high LF prevalences, to identify lymphedema cases. In this paper, we describe the characteristics and epidemiological distribution of the lymphedema cases identified.

\section{Methods}

\section{Study design and population}

A cross sectional study was performed in the health districts of Kolondieba, Bougouni and Kolokani from August 2016 to August 2018 (Fig. 1). LF mapping in 2004 had documented a LF prevalence of $66 \%$ in Kolondieba, $48 \%$ in Bougouni and 34\% in Kolokani [10]. Bougouni and Kolondieba are very large districts characterized by difficult geographic accessibility and relatively little knowledge (by the inhabitants) of the underlying causes of lymphedema.We screened for lymphedema cases using both passive and active case detection methods. With the passive case detection method, heads of community health centers and community health workers were asked to report people living with lymphedema. With the active case detection method a research team identified lymphedema cases through villages meetings, mobile phone calls and scheduled visits to remote villages.

We defined lymphedema as any non-traumatic progressive and evolving swelling of at least one upper or lower limb associated with a history of adenolymphangitis (ADL) episodes. For swelling of the lower limbs we used the Dreyer classification [11] to determine the stage of lymphedema as follows: stage I: reversible swelling that disappears spontaneously at night; stage II: nonreversible swelling that does not disappear spontaneously at night; stage III: presence of shallow skin folds; stage IV: presence of buds; stage V: presence of deep skin folds; stage VI: presence of mossy lesions; stage VII: inability to perform normal daily activities correctly and independently.

For swelling of the upper limbs we adapted the G Dreyer's classification as follows: Stage I: swelling of an arm reported by the affected person with history of an adenolymphagitis crisis but not necessarily observed by the investigator. Stage II any swelling of an arm without visible skin folds, Stage III any swelling of an arm with at least one skin fold. When more than one member was affected we considered the most advanced stage to classify lymphedema of the person. For both legs and arms, stage I assignments were based on history.

To estimate the prevalence of lymphedema per health district we divided the number of lymphedema cases identified by all the methods (active and passive) in each health district by the 2017 population size of the district multiplied by 100,000 . 


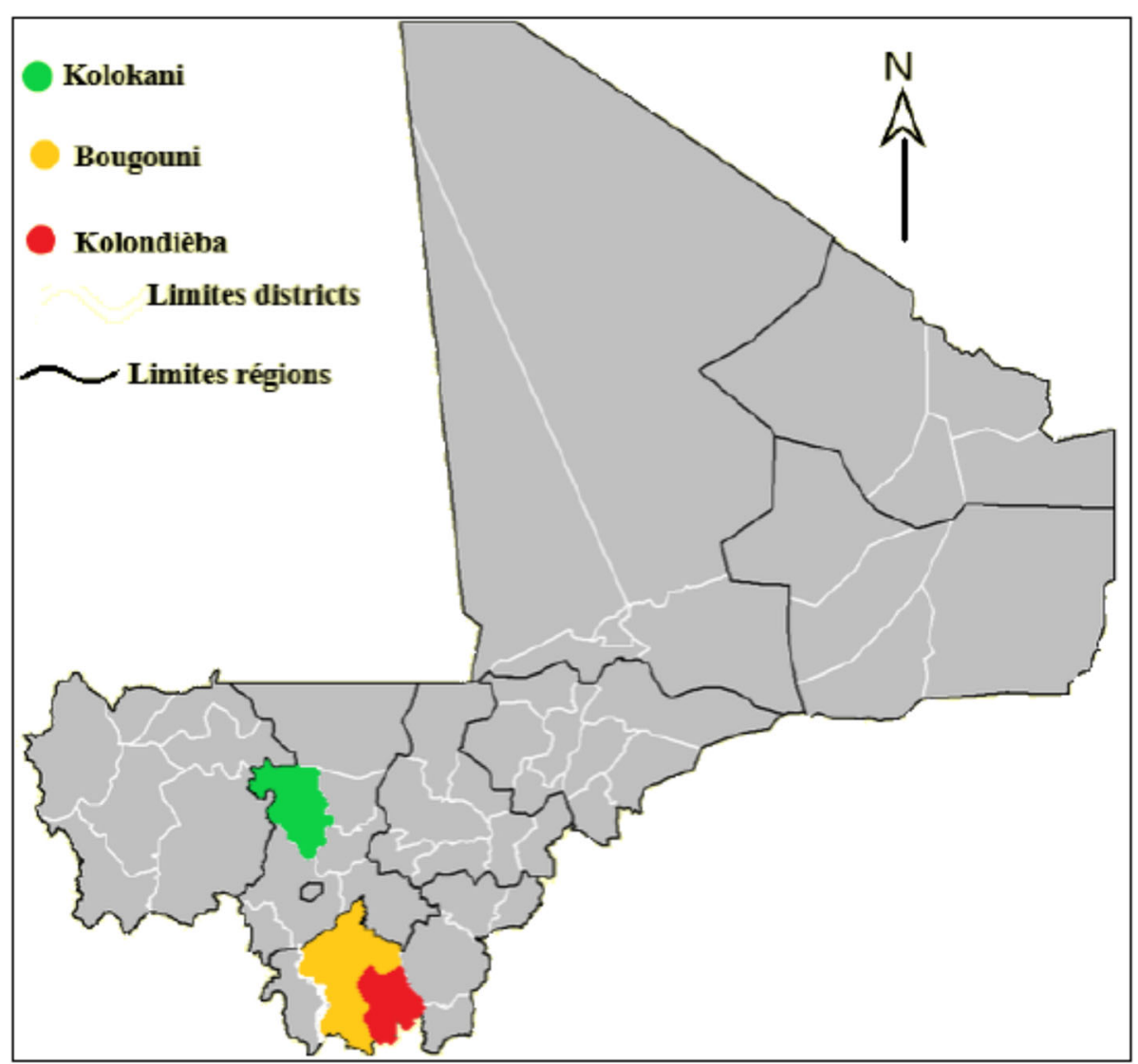

Source: International Center for Excellence in Research, Filariasis Research Unit, map made by Abdallah Amadou Diallo co-author of this manuscrit, 2019

Fig. 1 Map of Mali showing the three study districts in red (Kolondieba, Bougouni, and Kolokani) Source: International Center of Excellence in Research/Mali Filariasis research Unit, made by Abdallah Amadou Diallo co author of this manuscript, 2019

\section{Data collection and analysis}

Each case identified passively or actively was geopositioned using hand held GPS devices. We used medians to measure central tendency and chi-square test to determine statistical differences in lymphedema prevalence across categorical variables known to have a potential influence on lymphedema $[12,13]$, including clinical stages, different age groups and gender in all three health districts. Data were analyzed using Statistical Package for Social Sciences (SPSS) version 24.

\section{Results}

\section{Characteristics of people with lymphedema}

Three hundred thirty-nine people with lymphedema were identified, 175 (51.62\%) in Kolondieba, 116 (34.22\%) in Bougouni, and $48(14.16 \%)$ in Kolokani (Table 2). Overall, 286 (84.36\%) lymphedema cases were women (Table 1). The median age of all cases was 56 years (range 3-90). Lymphedema was reported in 266 (78.47\%) people aged 41 years and above compared to 73 $(21.53 \%)$ people below the age of 41 years $(\mathrm{Chi} 2=17.28$, $\mathrm{df}=5, p=0.004)$. All stages of lymphedema were observed except stage VII. Stage III lymphedema was observed in 131 (38.64\%), stage II in 108 (31.86\%), stage IV in $46(13.57 \%)$, stage $\mathrm{I}$ in $23(6.78 \%)$, stage $\mathrm{V}$ in 21 $(6.19 \%)$ and stage VI in ten (2.95\%) (Table 1).

\section{Staging and body localization of lymphedema in the three health districts}

Lymphedema affected the legs in 281(82.89\%), the arms in $42(12.39 \%)$ and both the arms and legs in $16(4.72 \%)$ $\left(\mathrm{Chi}^{2}=13.63, p=0.008\right)$ (Table 1$)$. Stage III was slightly more common in Kolondieba 71 (40.57\%) and in Bougouni $44(37.93 \%)$, stage II was most common in Kolokani $23(47.92 \%)$ and Bougouni had the highest prevalence of stage VI 7 (6.03\%). All stages were more frequent in the older age groups.

\section{Case detection approaches}

Of the 339 people with lymphedema, only 104 (30.68\%) were identified through passive case identification and $235(69.32 \%)$ by active case identification with no 
Table 1 Distribution of the lymphedema cases according to gender, age and body localization in three health districts of Mali

\begin{tabular}{|c|c|c|c|c|c|}
\hline & \multirow{3}{*}{$\begin{array}{l}\text { Kolondieba } \\
(N=175) \\
\text { Number }(\%)\end{array}$} & \multirow{3}{*}{$\begin{array}{l}\text { Bougouni } \\
(N=116) \\
\text { Number }(\%)\end{array}$} & \multirow{3}{*}{$\begin{array}{l}\text { Kolokani } \\
(N=48) \\
\text { Number (\%) }\end{array}$} & \multirow{3}{*}{$\begin{array}{l}\text { Total } \\
\text { Number (\%) }\end{array}$} & \multirow[b]{3}{*}{$p$ values } \\
\hline & & & & & \\
\hline & & & & & \\
\hline \multicolumn{6}{|l|}{ Sex } \\
\hline Female & $155(88.57 \%)$ & $97(83.63 \%)$ & $34(70.83 \%)$ & $286(84.36 \%)$ & \multirow[t]{2}{*}{0.01} \\
\hline Male & $20(11.43 \%)$ & $19(16.37 \%)$ & $14(29.17 \%)$ & $53(15.64 \%)$ & \\
\hline \multicolumn{6}{|l|}{ Age in years } \\
\hline Median age (range) & $54(13-88)$ & $56.5(2-90)$ & $56(18-84)$ & $56(2-90)$ & 0.40 \\
\hline \multicolumn{6}{|l|}{ Age group } \\
\hline $0-20$ & $2(1.14 \%)$ & $2(1.72 \%)$ & $2(2.08 \%)$ & $5(1.47 \%)$ & \multirow[t]{4}{*}{0.004} \\
\hline $21-40$ & 39 (22.29\%) & $19(16.38 \%)$ & $10(20.83 \%)$ & $68(20.06)$ & \\
\hline $41-60$ & $80(45.71 \%)$ & $55(47.41 \%)$ & $23(47.92 \%)$ & $158(46.61 \%)$ & \\
\hline$>=61$ & $54(30.86 \%)$ & $40(34.48 \%)$ & $14(29.17 \%)$ & 108 (31.86\%) & \\
\hline \multicolumn{6}{|l|}{ Anatomic location } \\
\hline Legs & $140(80.00 \%)$ & $104(89.65 \%)$ & $37(77.08 \%)$ & 281 (82.89\%) & \multirow[t]{3}{*}{0.008} \\
\hline Arms & 29 (16.57\%) & $8(6.90 \%)$ & $5(10.42 \%)$ & $42(12.39 \%)$ & \\
\hline Legs and Arms & $6(3.43 \%)$ & $4(3.45 \%)$ & $6(12.50 \%)$ & $16(4.72 \%)$ & \\
\hline \multicolumn{6}{|l|}{ Stage } \\
\hline । & $13(7.43 \%)$ & $5(4.31 \%)$ & $5(10.42 \%)$ & $23(6.78 \%)$ & \multirow[t]{6}{*}{0.02} \\
\hline$\|$ & $53(30.29 \%)$ & $32(27.59 \%)$ & $23(47.92 \%)$ & $108(31.86 \%)$ & \\
\hline III & $71(40.57 \%)$ & $44(37.93 \%)$ & $16(33.33 \%)$ & 131 (38.64\%) & \\
\hline IV & 27 (15.43\%) & $17(14.66 \%)$ & $2(4.17 \%)$ & $46(13.57 \%)$ & \\
\hline V & $8(4.57 \%)$ & $11(9.48 \%)$ & $2(4.17 \%)$ & 21 (6.19\%) & \\
\hline $\mathrm{VI}$ & $3(1.71 \%)$ & $7(6.03 \%)$ & $0(0.00 \%)$ & $10(2.95 \%)$ & \\
\hline
\end{tabular}

statistically difference observed $\mathrm{Chi}^{2}=3.323, \mathrm{df}=2$, $p=0.18$ (Table 2).

\section{Estimation of lymphedema prevalence}

The estimated prevalence of lymphedema in Kolondieba was 65.60 per 100,000 people, 19.17 per 100,000 people in Bougouni and 15.66 per 100,000 people in Kolokani; overall in the three health districts it was 28.77 per 100 , 000 people (Table 3 ).

\section{Examples of clinical presentations of lymphedema in Mali Case 1}

A woman between 30 and 40 years with stage VI lymphedema with swelling of the right leg from the foot to above the knee with mossy lesions (Fig. 2A). She reported two to three episodes of ADL per year.

\section{Case 2}

A woman above 65 years with lymphedema affecting both upper and lower limbs: right leg at stage III, left leg and right arm at stage II and the left arm at stage I (Fig. 2 $\mathrm{Bi}$ and $\mathrm{Bii})$. She reported at least two episodes of ADL per year.

\section{Case 3}

A mother between 20 and 30 years and her less than five -year-old daughter born with bilateral and symmetrical lymphedema at the lower limbs. The mother presented with stage VI lymphedema (Fig. 2D) and the daughter with stage III lymphedema (Fig. $2 \mathrm{Ci}$ and $2 \mathrm{Cii}$ ).

\section{Case 4}

A man between 15 and 20 years with lymphedema affecting the two legs. The two legs were at stage $\mathrm{V}$ (Fig. 2E). He reported having multiple episodes of ADL.

\section{Case 5}

A woman above 50 years old with stage III lymphedema in two arms (Fig. 2F). She reported having multiple ADL episodes over the past 10 years.

Case 6: A woman between 60 and 70 years had lymphedema in the right leg (2Gi) and left arm (2Gii) at stage II. She had no episodes of ADL for the last 3 years and had noticed a fairly dramatic decline in lymphedema size as she aged. 
Table 2 Number and percentage of lymphedema cases recorded per health district and per gender according to the method of identification

\begin{tabular}{|c|c|c|c|c|c|}
\hline \multirow{3}{*}{$\begin{array}{l}\text { Health } \\
\text { districts }\end{array}$} & \multirow[t]{3}{*}{ Gender } & \multirow{3}{*}{$\begin{array}{l}\text { Number } \\
\text { surveyed } \\
n(\%)\end{array}$} & \multicolumn{2}{|c|}{ Type of identification } & \multirow[t]{3}{*}{ Total } \\
\hline & & & Passive & Active & \\
\hline & & & $n(\%)$ & $n(\%)$ & \\
\hline \multirow[t]{2}{*}{ Kolondieba } & Male & $20(11.42 \%)$ & 7 (35.00\%) & $13(65.00 \%)$ & $20(100 \%)$ \\
\hline & Female & 155(88.58\%) & 45 (29.00\%) & $110(70.00 \%)$ & 155 (100\%) \\
\hline Sub-total $1^{*}$ & & $175(51.62 \%)$ & 52 (29.71\%) & 123 (70.29\%) & 175 (100\%) \\
\hline \multirow[t]{2}{*}{ Bougouni } & Male & $19(16.38 \%)$ & $3(15.79 \%)$ & $16(84.21 \%)$ & $19(100 \%)$ \\
\hline & Female & $97(83.62 \%)$ & 29 (29.90\%) & $68(70.10 \%)$ & 97 (100\%) \\
\hline Sub-total $2^{*}$ & & $116(34.22 \%)$ & 32 (27.59\%) & $84(72.41 \%)$ & $116(100 \%)$ \\
\hline \multirow[t]{2}{*}{ Kolokani } & Male & $14(29.17 \%)$ & $8(57.14 \%)$ & $6(42.86 \%)$ & $14(100 \%)$ \\
\hline & Female & $34(70.83 \%)$ & $12(35.29 \%)$ & $22(64.71 \%)$ & $34(100 \%)$ \\
\hline Sub-total $3^{*}$ & & $48(14.16 \%)$ & $20(41.66 \%)$ & $28(58.34 \%)$ & $48(100 \%)$ \\
\hline Total & & 339 (100\%) & 104 (30.68\%) & 235 (69.32\%) & 339 (100\%) \\
\hline
\end{tabular}

*Subtotal proportions were on the total cases of lymphedema identified

*Per identification type difference of reported lymphedema cases in the three health district $\left(\mathrm{Chi}^{2}=3.323, \mathrm{df}=2, p=0.18\right)$

\section{Case 7}

A woman between 60 and 70 years had a lymphedema of the left leg at stage $\mathrm{V}$ associated with dermal hypochromia (Fig. 2H). She reported having an average of three ADL attacks per year.

\section{Case 8}

A woman between 45 and 50 years with stage II lymphedema of the left arm (Fig. 2I). She had reported three ADL per year.

\section{Case 9}

A woman between 60 and 65 years with stage II lymphedema of the left leg and right arm and stage I lymphedema of the right leg (Fig. 2J). She had a chronic nonweeping ulceration at the medial malleolus of her left leg. She had reported having ADL attacks on average twice a month.

Case 10: A woman above 80 years old with lymphedema of two arms and one left leg at stage III (Fig. 2K). There is a history of lymphedema in her family. She had reported an average three ADL attacks per month.

\section{Discussion}

We identified 339 cases of lymphedema, mostly through active case finding, in three previously LF hyper-endemic health districts (Kolondieba, Bougouni, and Kolokani) in Mali. Most people with lymphedema were identified in Kolondieba, the district previously reported with the highest pre-MDA LF prevalence (66\%) [10]. Lymphedema was found predominantly among those in the older age group (median age 56 years); most cases occured in women (84\%). The preponderance of lymphedema among women is in line with observations in other LF endemic countries $[12,14,15]$. The age and gender distribution is different from what has been reported in podoconiosis which is mainly observed in individuals between 10 and 30 years old without any gender predominance $[4,13,16]$.

Lymphedemas were more frequently observed in those older than 41 years than in those in the lower age groups. We only observed 1 case of lymphedema (in the health district of Bougouni) in the age group of below 6 years after the MDA stopped in 2015. This difference is most likely a consequence of ivermectin- and albendazolebased MDA whereby the younger age groups had reduced exposure to LF parasites and therefore being less suspectible to develop lymphedema [17].

Table 3 Estimation of lymphedema prevalence per health district in three health district of Mali

\begin{tabular}{|c|c|c|c|c|c|}
\hline District & $\begin{array}{l}\text { Population size } \\
\text { in } 2017\end{array}$ & $\begin{array}{l}\text { Prevalence of LF during the } \\
\text { mapping in } 2005^{\mathrm{a}}\end{array}$ & $\begin{array}{l}\text { Number of lymphedema } \\
\text { carriers }\end{array}$ & $\begin{array}{l}\text { Estimated lymphedema prevalence } \\
\text { for } 100,000 \text { persons }\end{array}$ & $95 \% \mathrm{Cl}$ \\
\hline Kolondieba & 266,753 & $66 \%$ & 175 & $65.60 / 100,000$ & [55.89-75.32] \\
\hline Bougouni & 604,962 & $48 \%$ & 116 & $19.17 / 100,000$ & [15.69-22.66] \\
\hline Kolokani & 306,445 & $34 \%$ & 48 & $15.66 / 100,000$ & [11.23-20.09] \\
\hline Total & $1,178,160$ & $49 \%$ & 339 & $28.77 / 100,000$ & [25.71-31.84] \\
\hline
\end{tabular}

${ }^{\text {a }}$ Data are from the LF national report in 2005 

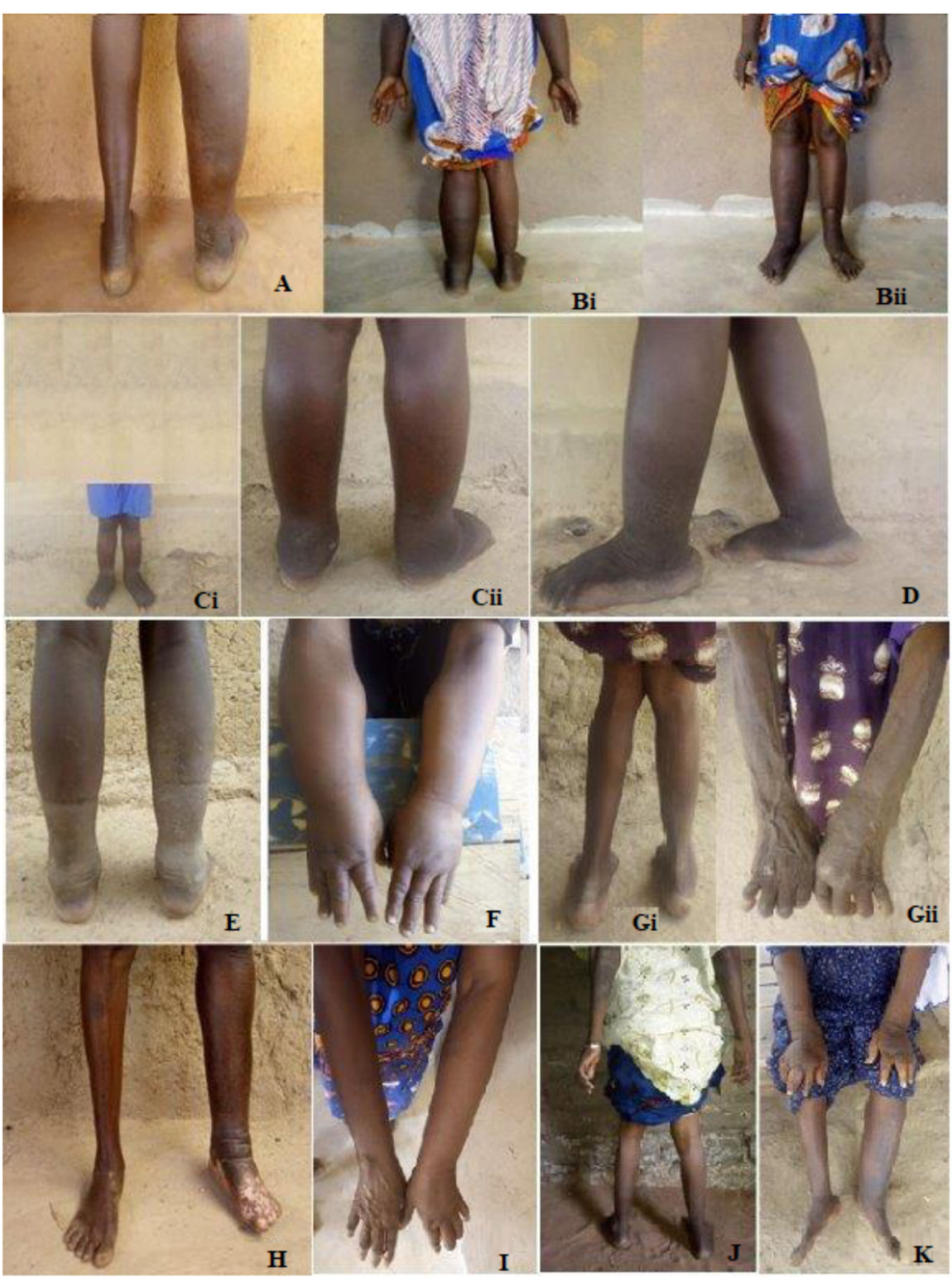

Source: International Center for Excellence in Research, images from Filariasis Research Unit, group author of this manuscript

Fig. 2 Variability of clinical presentation in patients with lymphedema in Mali. Panels showing unilateral lower extremity lymphedema (A), four limb lymphedema each at a different stage (Bi/Bii),familial lymphedema affected a children of less than 5 years old (Ci, Cii) and her mother (D), lymphedema of two legs in young man (E), lymphedema of two arms in woman(F), asymmetric lymphedema of left arm(Gii) and right leg (Gi), lymphedema of left leg with hypochromia (H), lymphedema of the left arm in woman (I), lymphedema of two legs and right arm at different stages in woman (J) and lymphedema of two arms and left leg in woman (K). Source: International Center of Excellence in Research/Mali images from Filariasis Research Unit group author of this manuscript

Most late stages of lymphedema were identified in Bougouni and Kolondieba, very large districts characterized by difficult geographic accessibility; these remote areas are locations in which lymphedema is believed to be caused by evil or malediction [18]. It is against this backdrop that our study population may have been difficult to mobilize, which in turn may have underestimated the true burden of lymphedema.
Our study highlights the importance of conducting active case detection which was more successful (approximatively $70 \%$ of cases detected) than passive case detection. This is explained by the fact that people with lymphedema usually consider their condition to be incurable and therefore may not consult health workers. Moreover, stigma concerning lymphedema may also play a role in further reducing uptake of community health services $[19,20]$. 
We observed several uncommon cases of lymphedema such as a case of congenital lymphedema also known as Milroy disease (case 3), an autosomal dominant disorder that causes lymphatic vessel dysfunction or absence of functional lymphatics [21]. We also observed a case of lymphedema affecting both upper and lower limbs at different stages (case 2) and a case of lymphedema affecting symmetrically two legs in a 18 year old young man without multiple hard skin nodules like podoconiosis (case 4) and those cases seem not related to LF [22].

In tropical countries, LF and podoconiosis are the most frequent causes of acquired lymphedema as opposed to European countries and in the United States where cancer-related treatment is the most frequent cause [23]. Medical record review of 511 patients with lymphedema attending a dermatological clinic in Tigray, Ethiopia between 2005 and 9, revealed that $9.2 \%$ of them were people with LF related lymphedema [24]. Intergrated morbidity mapping of LF and podoconiosis in 20 co-endemic districts in Ethiopia in 2018 detected 26,123 cases of lymphedema, $89.3 \%$ with bilateral lymphedema [25]. The prevalence of men reporting hydrocoele was low, 2.4 per 10,000 population. This large number of bilateral lymphedema cases and the low prevalence of hydrocoele suggest that most lymphedema cases in Ethiopia are caused by podoconiosis.

In Mali, LF control programs, akin to elsewhere in Africa, are more focused on MDA to interrupt transmission than on lymphedema morbidity management [26]. In a study conducted in Togo in 2007 , only $28.2 \%$ of 188 lymphedema cases were reported to have benefited from some sort of treatment. As lymphedema is a chronic, progressive condition, it is important to implement a morbidity management and disability prevention (MMDP) programme for LF as recommended by the WHO [26].

As limitations of this study, we need to mention that we did not perform a door-to-door survey and therefore we may have underestimated the prevalence of lymphedema. We also focused on case finding and did not assess co-morbidities such as scrotum swelling-hydrocele, treatment practices nor assessed the perception of communities about lymphedema.

\section{Conclusion}

Lymphedema remains a public health problem in previously LF endemic regions in Mali where transmission has been interrupted. Consequently it is imperative that active lymphedema case identification be scaled up in all previously LF endemic regions in Mali and that a MMDP programme at peripheral health system level is implemented to meet LF elimination goal in near future.

\section{Abbreviations}

ADL: Adenolymphangitis; FMOS: Faculté de Médicine et

d'Odontostomatologie (Faculty of Medicine and Odontostomatology); LF: Lymphatic filariasis; MDA: Mass drug administration; MMDP: Morbidity management and disability prevention; TAS: Transmission assessment surveys

\section{Acknowledgements}

The authors of this study gratefully acknowledge the contribution of all health staff from the health districts of Kolondieba, Bougouni and Kolokani and our study participants and of S Menon for reviewing the paper.

\section{Authors' contributions}

$H D, Y I C$ and TBN were responsible for the initial study protocol design. HD, FNK, SYC, SSD, MBS, LS, MEC, AAD, MS and YD implemented the protocol and collected the data and help for data analysis. HD, FNK, YIC and MS drafted the initial paper. RC, SD and TBN critically reviewed it and commented the paper. All authors read and approved the final paper.

\section{Funding}

This study was principally funded by the Division of Intramural Research, National Institute of Allergy and Infectious Diseases (NIAID) National Institutes of Health (NIH) project number Z01-Al001063 through the Filariasis Research Unit at the NIAID/Mali International Center of Excellence in Research (ICER) with additional support from a USAID Global Development Alliance grant number AID-OAA-G-14-000008. The funders have no role in the design, the implementation as well as the data analysis, interpretation, manuscript writting and publication for this paper.

\section{Availability of data and materials}

The datasets related to this paper are available through the NIAID/Mali International Center of Excellence in Research.

\section{Ethics approval and consent to participate}

Our study protocol was approved by the comité éthique de la Faculte de Medecine, de Pharmacie et d'Odontostomatologie de Bamako, an ethical committee of the Faculty of Medicine and Odonto Stomatology and the Faculty of Pharmacy of the University of Science, Techniques and Technologies of Bamako under the number (2016/ISO/CE/FMPOS). Participation in this study was entirely voluntary. Before undertaking any research activity, written informed consent (and/or assent) was obtained from every study participant or their parents/legal guardians. The main study, a multi-country was registered in clinical trial.gov under the number NCT02927496.

\section{Consent for publication}

After obtaining written informed consent to participate in this study, the participants and/or their parents/legal guardians have given their written informed consent (and/or assent) to publish their pictures without naming them in the peer review journals and or during scientific presentations and meetings.

\section{Competing interests}

The authors declare that they have no competing interests.

\section{Author details}

${ }^{1}$ Filariasis Unit, International Center of Excellence in Research, Faculty of Medicine and Odontostomatology, BP :1805, Point G, Bamako, Mali. ${ }^{2}$ Global Health Institute, Faculty of Medicine \& Health Sciences, University of Antwerp, Antwerp, Belgium. ${ }^{3}$ Centre National d'Appui à la lutte contre la Maladie, Bamako, Mali. ${ }^{4}$ Laboratory of Parasitic Diseases, National Institute of Allergy and Infectious Diseases, National Institutes of Health, Bethesda, MD 20892, USA.

Received: 15 July 2019 Accepted: 8 January 2020

Published online: 15 January 2020

\section{References}

1. Kerchner K, Fleischer A, Yosipovitch G. Lower extremity lymphedema update: pathophysiology, diagnosis, and treatment guidelines. J Am Acad Dermatol. 2008:59:324-31. https://doi.org/10.1016/j.jaad.2008.04.013. 
2. Gaffney RM, Casley-Smith JR. Excess plasma proteins as a cause of chronic inflammation and lymphoedema: biochemical estimations. J Pathol. 1981; 133:229-42. https://doi.org/10.1002/path.1711330306.

3. Filariose lymphatique. https://www.who.int/fr/news-room/fact-sheets/detail/ lymphatic-filariasis. Accessed 14 Apr 2019.

4. Davey G, Newport M. Podoconiosis: the most neglected tropical disease? Lancet. 2007;369:888-9. https://doi.org/10.1016/S0140-6736(07)60425-5.

5. Price EW. The association of endemic elephantiasis of the lower legs in East Africa with soil derived from volcanic rocks. Trans R Soc Trop Med Hyg. 1976;70:288-95. https://doi.org/10.1016/0035-9203(76)90078-X.

6. Gassama M, Karabinta Y, Diarra M, Koné M, Tall K, Sanogo AM, et al. Aspects Épidémiologiques et Cliniques du Lymphœedème dans le Service de Dermatologie du CHU Gabriel Touré (Bamako). Health Sci Dis. 2018;29(1):73-76.

7. Nutman TB. Insights into the pathogenesis of disease in human lymphatic filariasis. Lymphat Res Biol. 2013;11:144-8. https://doi.org/10.1089//rb.2013.0021.

8. Coulibaly YI, Dembele B, Diallo AA, Kristensen S, Konate S, Dolo H, et al. Wuchereria bancrofti transmission pattern in southern Mali prior to and following the institution of mass drug administration. Parasit Vectors. 2013;6: 247. https://doi.org/10.1186/1756-3305-6-247.

9. Dolo H, Coulibaly YI, Dembele B, Guindo B, Coulibaly SY, Dicko I, et al. Integrated seroprevalence-based assessment of Wuchereria bancrofti and Onchocerca volvulus in two lymphatic filariasis evaluation units of Mali with the SD bioline Onchocerciasis/LF IgG4 rapid test. PLoS Negl Trop Dis. 2019; 13:e0007064. https://doi.org/10.1371/journal.pntd.0007064.

10. Dembélé $M$, Bamani $S$, Dembélé $R$, Traoré MO, Goita $S$, Traoré MN, et al. Implementing preventive chemotherapy through an integrated National Neglected Tropical Disease Control Program in Mali. PLoS Negl Trop Dis. 2012;6:e1574. https://doi.org/10.1371/journal.pntd.0001574.

11. Dreyer $G$, Addiss D, Dreyer P, Norões J. Basic lymphoedema management: treatment and prevention of problems associated with lymphatic filariasis. Hollis: Hollis Publishing Company; 2002. p. 112.

12. Grada AA, Phillips TJ. Lymphedema: pathophysiology and clinical manifestations. J Am Acad Dermatol. 2017;77:1009-20. https://doi.org/10. 1016/j.jaad.2017.03.022

13. Greene AK, Grant FD, Slavin SA. Lower-extremity lymphedema and elevated body-mass index. N Engl J Med. 2012;366:2136-7. https://doi.org/10.1056/ NEJMc1201684.

14. Richard SA, Mathieu E, Addiss DG, Sodahlon YK. A survey of treatment practices and burden of lymphoedema in Togo. Trans R Soc Trop Med Hyg. 2007;101:391-7. https://doi.org/10.1016/j.trstmh.2006.08.011.

15. Walsh V, Little K, Wiegand R, Rout J, Fox LM. Evaluating the burden of lymphedema due to lymphatic filariasis in 2005 in khurda district, Odisha state, India. PLoS Negl Trop Dis. 2016;10:e0004917. https://doi.org/10.1371/ journal.pntd.0004917.

16. Schook CC, Mulliken JB, Fishman SJ, Grant FD, Zurakowski D, Greene AK. Primary lymphedema: clinical features and management in 138 pediatric patients. Plast Reconstr Surg. 2011;127:2419-31. https://doi.org/10.1097/PRS. Ob013e318213a218.

17. Ramaiah KD, Ottesen EA. Progress and impact of 13 years of the global programme to eliminate lymphatic filariasis on reducing the burden of filarial disease. PLoS Negl Trop Dis. 2014;8:e3319. https://doi.org/10.1371/ journal.pntd.0003319.

18. Abdulmalik J, Nwefoh E, Obindo J, Dakwak S, Ayobola M, Umaru J, et al. Emotional difficulties and experiences of stigma among persons with lymphatic Filariasis in plateau state, Nigeria. Health Hum Rights. 2018;20:27-40.

19. Cassidy T, Worrell CM, Little K, Prakash A, Patra I, Rout J, et al. Experiences of a community-based lymphedema management program for lymphatic Filariasis in Odisha state, India: an analysis of focus group discussions with patients, families, Community Members and Program Volunteers. PLoS Negl Trop Dis. 2016;10:e0004424. https://doi.org/10.1371/journal.pntd.0004424.

20. Greene AK, Slavin SA, Brorson H, editors. Lymphedema: presentation, diagnosis, and treatment. Cham: Springer International Publishing; 2015. https://doi.org/10.1007/978-3-319-14493-1.

21. Yimer M, Hailu T, Mulu W, Abera B. Epidemiology of elephantiasis with special emphasis on podoconiosis in Ethiopia: a literature review. J Vector Borne Dis. 2015;52:111-5.

22. Rockson SG, Rivera KK. Estimating the population burden of lymphedema. Ann N Y Acad Sci. 2008;1131:147-54. https://doi.org/10.1196/annals.1413.014.

23. Padovese V, Marrone R, Dassoni F, Vignally P, Barnabas GA, Morrone A. The diagnostic challenge of mapping elephantiasis in the Tigray region of northern Ethiopia. Int J Dermatol. 2016;55:563-70. https://doi.org/10.1111/ ijd.13120.

24. Kebede B, Martindale S, Mengistu B, Kebede B, Mengiste A, H/Kiros F, et al. Integrated morbidity mapping of lymphatic filariasis and podoconiosis cases in 20 co-endemic districts of Ethiopia. PLoS Negl Trop Dis. 2018;12: e0006491. https://doi.org/10.1371/journal.pntd.0006491.

25. Deribe K, Cano J, Trueba ML, Newport MJ, Davey G. Global epidemiology of podoconiosis: a systematic review. PLoS Negl Trop Dis. 2018;12:e0006324. https://doi.org/10.1371/journal.pntd.0006324.

26. World Health Organization. Managing morbidity and preventing disability in the Global Programme to Eliminate Lymphatic Filariasis: WHO position statement. Wkly Epidemiol Rec = Relevé épidémiologique hebdomadaire. 2011;86(51-52):581-5.

\section{Publisher's Note}

Springer Nature remains neutral with regard to jurisdictional claims in published maps and institutional affiliations.

\section{Ready to submit your research? Choose BMC and benefit from:}

- fast, convenient online submission

- thorough peer review by experienced researchers in your field

- rapid publication on acceptance

- support for research data, including large and complex data types

- gold Open Access which fosters wider collaboration and increased citations

- maximum visibility for your research: over $100 \mathrm{M}$ website views per year

At BMC, research is always in progress.

Learn more biomedcentral.com/submissions 